\title{
Mesothelioma and a high potassium
}

\section{A Elmarimi BCh $\mathrm{MRCP}^{1} \quad$ A Kendall $\mathrm{BM} \mathrm{MRCP}^{2}$ $P$ Ellis MD FRACP ${ }^{2}$ C D Shee MD FRCP ${ }^{1}$}

J R Soc Med 2004;97:390-391

When hyperkalaemia coincides with thrombocythaemia, it may prove to be pseudohyperkalaemia.

\section{CASE HISTORY}

A man of 52 was referred after four months of right-sided chest pain with dyspnoea and lethargy. He was a nonsmoker who worked as a toolmaker and had no known exposure to asbestos. CT showed irregular pleural thickening extending to the mediastinal and diaphragmatic pleura, and percutaneous biopsy confirmed malignant mesothelioma. He was anaemic (haemoglobin $9.1 \mathrm{~g} / \mathrm{dL}$ ) with a raised white cell count $\left(15.5 \times 10^{9} / \mathrm{L}\right)$ and platelet count $\left(1171 \times 10^{9} / \mathrm{L}\right)$. Urea and creatinine were normal but serum potassium was slightly raised at $5.5 \mathrm{mmol} / \mathrm{L}$. He was referred to a cancer centre for palliative chemotherapy, by which time his haemoglobin had dropped to $6.9 \mathrm{~g} / \mathrm{dL}$; his white cell count had risen to $21 \times 10^{9} / \mathrm{L}$ and the platelet count to $1400 \times 10^{9} / \mathrm{L}$. Serum folate and vitamin B12 levels were normal, serum ferritin raised. After transfusion of blood he was treated with mitomycin, vinblastine and cisplatin (MVP). At the cancer centre his serum potassium was $7.1 \mathrm{mmol} / \mathrm{L}$ (sodium, creatinine and cortisol normal). After treatment with intravenous glucose and insulin he was started on oral Calcium Resonium (calcium polystyrene sulphonate), an ion-exchange resin. By now the white cell count was $31.5 \times 10^{9} / \mathrm{L}$ and the platelet count $1735 \times 10^{9} / \mathrm{L}$ (it peaked at 2000).

After four three-weekly cycles of chemotherapy the patient did not seem to be responding, and six months after initial diagnosis he was referred back to his local hospital for follow-up and palliative care. The serum potassium was then rechecked and proved to be $6.2 \mathrm{mmol} / \mathrm{L}$; however, a simultaneous plasma potassium was only $5.1 \mathrm{mmol} / \mathrm{L}$ confirming the clinical suspicion of pseudohyperkalaemia secondary to thrombocytosis. Calcium Resonium was stopped. Over the next few months his health improved, he returned to full-time work and his chest radiograph showed minimal residual tumour. During this remission the serum potassium dropped to $5.0 \mathrm{mmol} / \mathrm{L}$, haemoglobin

'Department of Medicine, Queen Mary's Hospital, Sidcup, Kent DA14 6LT; ${ }^{2}$ Medical Oncology Department, Guy's Hospital, London SE1 9RT, UK

Correspondence to: Dr C D Shee

E-mail: charles.shee@qms.nhs.uk rose to $12.0 \mathrm{~g} / \mathrm{L}$, WBC fell to $13.6 \times 10^{9} / \mathrm{L}$ and platelets fell to $456 \times 10^{9} / \mathrm{L}$. After eighteen symptom-free months the tumour recurred and he did not respond to further chemotherapy. On the day he died he was brought to his local hospital because of chest pain and dyspnoea. Renal function was normal, platelet count $1400 \times 10^{9} / \mathrm{L}$, serum potassium $6.8 \mathrm{mmol} / \mathrm{L}$. While awaiting his case notes and being unaware of his previous diagnosis of pseudohyperkalaemia, the admitting team treated him with intravenous glucose and insulin to lower the potassium.

\section{COMMENT}

The thrombocytosis associated with this patient's mesothelioma caused an in-vitro rise in serum potassium. Suspicion of pseudohyperkalaemia was confirmed when plasma potassium proved to be substantially lower and when both platelet count and serum potassium fell with chemotherapy.

There is a recognized association between malignant mesothelioma and thrombocytosis. ${ }^{1}$ The rise in platelets and white cell count is thought to be largely due to increased production of interleukin 6 by the tumour, ${ }^{2,3}$ with other thrombopoietic substances possibly involved as well. ${ }^{4}$ The anaemia in our patient was probably that of 'chronic disease' since it was associated with a high ferritin level and improved when his tumour regressed.

Thrombocytosis can be associated with a raised serum potassium, ${ }^{5,6}$ but we are not aware of this having been reported in mesothelioma. The mechanism of the hyperkalaemia is probably in-vitro release of potassium from cells undergoing lysis, the true plasma potassium in vivo being normal. This phenomenon is easily forgotten; the present patient was treated with intravenous glucose and insulin on two occasions to lower the potassium and had also been treated with an oral ion exchange resin. We know of another patient with pseudohyperkalaemia (secondary to thrombocytosis and myeloproliferative disorder) who has likewise been given glucose and insulin infusions on two occasions, unnecessarily.

\section{REFERENCES}

1 Olsen LL, Thorshauge H. Thrombocytosis in patients with malignant pleural mesothelioma. Cancer 1988;62:1194-6

2 Higashihara M, Sunaga S, Tange T, Oohashi H, Kurokawa K. Increased secretion of Interleukin-6 in malignant mesothelioma from a patient with marked thrombocytosis. Cancer 1992;70:2105-8

3 Nakano T, Chahinian AP, Shinjo M, et al. Interleukin-6 and its relationship to clinical parameters in patients with malignant pleural mesothelioma. Br J Cancer 1998;77:907-12

4 Tange T, Hasegawa Y, Oka T, et al. Establishment and characterisation of a new human mesothelioma line (T-85) from malignant mesothelioma with marked thrombocytosis. Pathol Int 1995; 45:791-800

5 Wulkan RW, Michiels JJ. Pseudohyperkalemia in thrombocythaemia. J Clin Chem Clin Biochem 1990;28:489-91

6 Seah TG, Lew TW, Chin NM. A case of pseudohyperkalemia and thrombocytosis. Ann Acad Med Singapore 1998;27:442-3 